\title{
RECIL PR
}

National Cancer Institute

\section{Source}

National Cancer Institute. RECIL PR. NCI Thesaurus. Code C159619.

Greater than or equal to 30 percent decrease in the sum of longest diameters of target lesions but not a complete response. 